\title{
FIBRIN SEALANT, APROTININ, AND IMMUNE RESPONSE IN CHILDREN UNDERGOING OPERATIONS FOR CONGENITÁL HEART DISEASE
}

Albertus M. Scheule, MD

Wolfram Beierlein, MS

Hans P. Wendel, PhD

Friedrich S. Eckstein, MD

Markus K. Heinemann, MD

Gerhard Ziemer, MD
Objective: Most commercially available fibrin sealants contain aprotinin in doses of 1500 kallikrein inactivator units per milliliter. They are used in many operative disciplines. An elevated risk of hypersensitivity reactions exists at reexposure to aprotinin. Our aim was to examine the immunogenic potency of aprotinin as a fibrin sealant content. Methods: We investigated 49 children with operatively treated congenital heart disease. All patients received aprotinin only topically as contained in fibrin sealant. Serum samples were drawn preoperatively, 1 week, 2 weeks, 6 weeks, and approximately 1 year after operation. They were analyzed for aprotinin-specific immunoglobulin $\mathbf{G}$ antibodies with a standard enzyme-linked immunosorbent assay and a fluorescence enzyme immunoassay for aprotinin-specific immunoglobulin $\mathrm{E}$ antibodies. Results: At 1 week, 2 weeks, 6 weeks, and 1 year, we found prevalences of $8 \%$ ( 2 of 26$), 8 \%$ ( 2 of 24$), 6 \%$ (3 of 49), and $0 \%$ for aprotinin-specific Immunoglobulin $\mathrm{E}$, and for aprotinin-specific immunoglobulin G 8\% ( 2 of 26), 17\% (4 of 24), 39\% (19 of 49), and 12\% (5 of 41). The doses of aprotinin given did not differ significantly in antibodynegative and antibody-positive patients; no significant factors could predict the immune response. Conclusions: Our findings show the existence of a subgroup of patients who had aprotinin-specific antibodies develop after topical aprotinin application. Any use of aprotinin must be carefully documented. If aprotinin use is planned in patients who previously underwent a surgical procedure, preexposure to aprotinin in any form must be sought to avoid unexpected anaphylactic reactions. The necessity itself and alternatives for aprotinin as a stabilizing agent in fibrin sealants merit consideration. (J Thorac Cardiovasc Surg 1998;115:883-9)
A protinin is a polyvalent proteinase inhibitor from bovine organs. Since the 1980 s, it has been used in high doses of several million kallikrein inactivator units (KIU) for its beneficial effect on perioperative blood loss and transfusion requirements in cardiac operations. $^{1,2}$ It is also used in small concentrations of about $1500 \mathrm{KIU} / \mathrm{ml}$ in commercially available fibrin sealants because it significantly extends the

From the Department of Surgery, Division of Thoracic, Cardiac and Vascular Surgery, Eberhard-Karls-University, Tuebingen, Germany.

Received for publication May 15, 1997; revisions requested August 12, 1997; revisions received Sept. 26, 1997; accepted for publication Sept. 29, 1997.

Address for reprints: Prof. Dr. med. G. Ziemer, Division of Thoracic, Cardiac and Vascular Surgery, Eberhard-KarlsUniversity, Tuebingen, Hoppe-Seyler-Strasse 3, D-72076 Tuebingen, Germany.

Copyright (c) 1998 by Mosby, Inc.

$0022-5223 / 98 \$ 5.00+0 \quad \mathbf{1 2 / 1 / 8 6 7 2 2}$ resorption of the fibrin clot in the physiologic environment. ${ }^{3}$ These biologic sealants are increasingly used in many surgical disciplines. ${ }^{4,5}$ In Europe and several Asian countries these products have been commercially available since the early 1980s. The U. S. Food and Drug Administration is presently considering approval of a commercially available fibrin sealant in the United States.

As a foreign protein composed of 58 amino acid residues with a molecular weight of 6512 daltons, aprotinin is capable of triggering hypersensitivity reactions, particularly after systemic reexposure. 6 The frequency of severe allergic and pseudoallergic reactions after systemic reexposure is estimated to be between $0.1 \%$ and $5.8 \% .^{7,8}$ There are also reports of fatal adverse reactions. ${ }^{9,10}$

Antigen-specific antibodies play a decisive role in adverse reactions of sensitized patients at reexposure to antigens: antibodies of the immunoglobulin (Ig) E class are responsible for "true" anaphylactic 
Table I. Distribution of patients according to age and lesions

\begin{tabular}{ccccc}
\hline & \multicolumn{4}{c}{ Age (mo) } \\
\cline { 2 - 5 } & $0 \leq 1$ & $1 \leq 12$ & $>12$ & Total \\
\hline $\begin{array}{c}\text { Acyanotic } n \\
(\% \text { of total })\end{array}$ & $3(6.1)$ & $8(16.3)$ & $19(38.8)$ & $30(61.2)$ \\
$\begin{array}{c}\text { Cyanotic } n \\
(\% \text { of total })\end{array}$ & $4(8.2)$ & $7(14.3)$ & $8(16.3)$ & $19(38.8)$ \\
\hline
\end{tabular}

reactions ${ }^{11}$; antibodies of the $\operatorname{IgG}$ class may trigger anaphylactoid reactions through the involvement of the complement system. ${ }^{12,13}$ Such anaphylactoid reactions cannot be clinically distinguished from true anaphylactic reactions.

The incidence of specific IgE antibodies within 8 weeks after a course of several infusions of aprotinin for acute pancreatitis was estimated to be about $32 \%$ (95\% confidence interval: $19 \%$ to $48 \%$ ) (14 of 44) of patients. ${ }^{14}$ The prevalence of aprotinin-specific IgG antibodies was estimated to be about $40 \%$ to $50 \%$ of adult patients exposed to one first systemic high dose of aprotinin during cardiac operation half a year earlier. ${ }^{15,16}$

Recent articles discussed the immunogenic effect of low aprotinin doses such as those contained in commercially available fibrin sealants. ${ }^{10,17}$ There are two case reports of severe unexpected reactions accompanied by circulatory collapse in which the aprotinin component of fibrin sealant could be identified as the causative agent. ${ }^{18,19}$

The immunogenic effect of aprotinin contained in commercially available fibrin sealants has not yet been examined in a clinical study. No data are available for adults or children about the prevalence and time course of aprotinin-specific antibodies after a first and single exposure to commercially available fibrin sealant.

\section{Patients and methods}

Patients Forty-nine children (29 male, 20 female) undergoing cardiac operations between April 1995 and November 1995 and receiving fibrin sealant for the first time (median dose: $2.0 \mathrm{ml}, 7090 \mathrm{KIU} / \mathrm{m}^{2}$ body surface area) were the subjects of the study. This represents $38 \%$ of all children (49 of 130) operated in our division during that time frame. The median age of the patients was 15.2 months (50\% range: 4 months to $3^{11 / 12}$ years). The corrective operations comprised the whole spectrum of congenital heart disease from direct atrial septal defect closure to complex reconstructions and definitive surgery in univentricular hearts.

Table I shows the distribution of the patients according to age and lesions.
Forty-three patients $(88 \%)$ were operated on with the use of cardiopulmonary bypass, 17 of them with deep hypothermic circulatory arrest ( 17 of $43,40 \%$ ); there were six closed procedures, such as palliative shunts or coarctectomy.

Sixteen of the 49 children underwent cardiac reoperations. Most of the primary operations consisted of valvotomy for critical aortic stenosis or shunt procedures in cyanotic newborns with complex disease. Neither application of fibrin sealant nor infusion of aprotinin had been documented for these primary operations.

Methods All parents were informed about the aim of the study and consent was given in writing. The decision to use fibrin sealant was only made intraoperatively because of operative necessity. All patients received 0.7 to $12 \mathrm{ml}$ of a commercially available fibrin sealant (Tissucol Duo S, Immuno, Vienna, Austria), consisting of two components: a plasma fraction (containing 70 to $110 \mathrm{mg}$ fibrinogen, 2 to $9 \mathrm{mg}$ plasma fibronectin, 10 to $50 \mathrm{U}$ coagulation factor VIII, 0.02 to $0.08 \mathrm{mg}$ plasminogen (all human), and 3000 KIU (i.e., $0.42 \mathrm{mg}$ ) bovine aprotinin per $1 \mathrm{ml}$ and a thrombin fraction (containing $500 \mathrm{U}$ human thrombin and $5.88 \mathrm{mg}$ calcium chloride per $1 \mathrm{ml}$ ).

In all patients, aprotinin was applied only topically in the mediastinum, but not systemically. Children with previous contact with aprotinin, as ascertained from their history, documentation in the chart, and a preoperative serum sample positive for aprotinin-specific antibodies, were excluded from the study. To avoid allergic reactions or immunologic interference, we purposely did not perform skin testing.

A complete history of allergies was taken, including the patient's own and their family's history of atopic diathesis. The questionnaire also covered the patient's complete medical history emphasizing immunologically important factors such as susceptibility to infections (children having had two or more infections during the 3 months preceding the operation were considered as being susceptible to infections), the patient's history of long-term drug therapy, and vaccinations.

Serum samples were obtained preoperatively, 1 week, 2 weeks, 6 weeks, and approximately 1 year postoperatively. They were centrifuged for 15 minutes at $10^{\circ} \mathrm{C}$ at $1200 \mathrm{G}$, and stored at $-20^{\circ} \mathrm{C}$ until the in vitro tests were performed.

One week after the operation we obtained the sera of 26 patients and after 2 weeks those of 24 patients. At a routine examination 6 weeks postoperatively we obtained the sera of all 49 patients. After 1 year, we obtained the sera of 41 children: two others had died and six were lost to follow-up or refused further blood sampling. Preoperative sera had been stored from all 49 patients. No child underwent reoperations during the observation time.

Analyses. Analyses included assays for the detection of total serum $\operatorname{IgE}$ and $\operatorname{IgG}$ levels and aprotinin-specific $\operatorname{IgG}$ and $\operatorname{IgE}$ antibodies with the techniques described below:

UniCAP System. Total serum IgE and aprotinin-specific $\mathrm{IgE}$ antibodies were quantified with the automatic Pharmacia UniCAP device (Pharmacia \& Upjohn, Uppsala, Sweden) using a fluorescence enzyme immunoassay (FEIA). Quantitative expression of results was obtained by using standard reagents calibrated against World 
Table II. RAST/FEIA classes

\begin{tabular}{|c|c|c|c|c|c|c|c|}
\hline & \multicolumn{7}{|c|}{ RAST/FEIA classes } \\
\hline & 0 & $I$ & $I I$ & III & $I V$ & $V$ & $V I$ \\
\hline Aprotinin-specific $\operatorname{IgE}\left(\mathrm{kU}_{\mathrm{A}} / \mathrm{L}\right)$ & $<0.35$ & $\geq 0.35$ & $\geq 0.7$ & $\geq 3.5$ & $\geq 17.5$ & $\geq 50$ & $\geq 100$ \\
\hline Antibody level & $\begin{array}{l}\text { Absent or } \\
\text { undetectable }\end{array}$ & Low & Moderate & High & Very high & Very high & Very high \\
\hline
\end{tabular}

Health Organization reference preparations for human $\operatorname{IgE}(75 / 502)$.

Total serum IgE levels greater than 120 kilo-Units per liter were considered elevated.

Concentrations of aprotinin-specific IgE are expressed in kilo-Units of allergen-specific IgE per liter $\left(\mathrm{kU}_{\mathrm{A}} / \mathrm{L}\right)$ and evaluated according to the conventional radioallergosorbent classes: values of $0.35 \mathrm{kU}_{\mathrm{A}} / \mathrm{L}$ and greater represent a progressive increase in the relative concentration of allergen-specific antibodies (Table II). Values less than 0.35 $\mathrm{kU}_{\mathrm{A}} / \mathrm{L}$ represent absent or undetectable levels of allergenspecific antibodies.

Enzyme-linked immunosorbent assay Ninety-six-WellImmuno-Plates (Maxisorp, Nunc GmbH, Wiesbaden, Germany) were coated with an antigen solution containing $5 \mu \mathrm{g}$ aprotinin (36 KIU Trasylol, Bayer, Leverkusen, Germany) per milliliter Tris-buffered saline solution (Sigma Chemical Company, St. Louis, Mo.). The plates were incubated overnight at $4^{\circ} \mathrm{C}$ and washed five times with $300 \mu \mathrm{l}$ TTBS (Tris-buffered saline solution plus $0.05 \%$ Tween 20; Merck-Schuchardt, Hohenbrunn, Germany) per well. This washing procedure was repeated after each subsequent step. The wells were blocked with $300 \mu \mathrm{l}$ blocking reagent (Blocking reagent for enzyme-linked immunosorbent assay [ELISA], Boehringer Mannheim, Germany) per well and incubated for 60 minutes at room temperature. Then $100 \mu \mathrm{l}$ samples or control serum diluted $1: 100$ in $0.9 \% \mathrm{NaCl}$ were added per well. Serum with known concentrations of aprotinin-specific antibodies (IgG: $114 \mathrm{mg} / \mathrm{L}$, RAST-FEIA), obtained from a patient who had had an anaphylactic reaction to aprotinin as described elsewhere, ${ }^{20}$ served as a positive reference. Six dilutions from $1: 25$ to $1: 1600$ were used to establish the reference curve. Negative controls were obtained from a pool of 20 donors without prior contact with aprotinin. $\mathrm{NaCl}, 0.9 \%$, was used as a blank. After 120 minutes of incubation at room temperature, $100 \mu \mathrm{l}$ alkaline phosphatase-conjugated goat anti-human $\gamma$-chain specific IgG (Sigma) were added per well. The antibody-enzymeconjugate was used in a dilution of 1:10,000 in 1\% bovine serum albumin (Sigma) and TTBS. The plates were incubated again for 90 minutes at room temperature, followed by the addition of $100 \mu \mathrm{l}$-nitrophenyl phosphate solution (Sigma Fast pNPP Tablets, soluble alkaline phosphatase substrate, Sigma) per well, and the absorbance was read at $405 \mathrm{~nm}$ using an ELISA-Reader (Dynatech Lab, Denkendorf, Germany). Because the semilogarithmic reference curve was linear for aprotininspecific $\operatorname{IgG}$ concentrations of 10 to $400 \mathrm{mg} / \mathrm{L}$ and the mean plus three standard deviations of 20 negative controls was less than $10 \mathrm{mg} / \mathrm{L}$, serum concentrations higher than $10 \mathrm{mg} / \mathrm{L}$ of aprotinin-specific $\mathrm{IgG}$ were considered positive for aprotinin-specific IgG.

Western blotting. A solution of reduced aprotinin (Trasylol, heated for 5 minutes at $95^{\circ} \mathrm{C}$ with addition of 1 grain of dithiothreitol) was concentrated in a polyacrylamide gel by means of electrophoresis and subsequently transferred to a nitrocellulose membrane (Probind 45, Pharmacia, Uppsala, Sweden) with an electroblotting technique with the appropriate material (Mini-Protean II Multiscreen, Bio-Rad, Munich, Germany, and Multiphor II, Pharmacia-LKB, Bromma, Sweden). These membranes were then incubated with the test specimen and the control specimen in the appropriate test system (MiniProtean II Multiscreen). Aprotinin-specific IgG antibodies contained in the 1:100 in TBS (Loewe Biochemica, Otterfing, Germany) diluted sera bind to the nitrocellulose, on which they are visualized by an enzymatic staining reaction (5-bromo-4-chloro-3-indolyl phosphate/nitroblue tetrazolium, Sigma Fast BCIP/NBT Tablets, Sigma) after incubation with a secondary enzyme-labeled antihuman IgG-antibody diluted 1:30,000 in TBS (goat antihuman IgG-AP, $\gamma$-chain specific, Sigma). The test bonds were compared with those of the control sera and divided by sight into the categories "positive," "questionably positive," and "negative."

Nephelometry. The evaluation of total serum IgG concentrations was performed in the clinic's routine laboratory with a Behring Nephelometer (Behringwerke AG, Marburg, Germany) according to the operating instructions and with the appropriate reagents purchased from Behring.

Statistical analysis. Values that are not normally distributed are shown as medians with $50 \%$ range; normally distributed values are portrayed as means with standard deviation. Percentages are presented with $95 \%$ confidence intervals for the probability based on the binomial distribution in brackets. The influence of antigen dose, age, body surface area, and preexisting allergies on the prevalence of antibody formation was tested with a multiple logistic regression analysis using the statistical package JMP.

\section{Results}

Aprotinin-specific antibodies. The number of patients positive for aprotinin-specific antibodies at the respective dates of blood-sampling (i.e., prevalence) is shown in Fig. 1.

The incidence of aprotinin-specific IgE antibodies within the observation time was $14.3 \%$ (5\% to $24 \%$ ), 


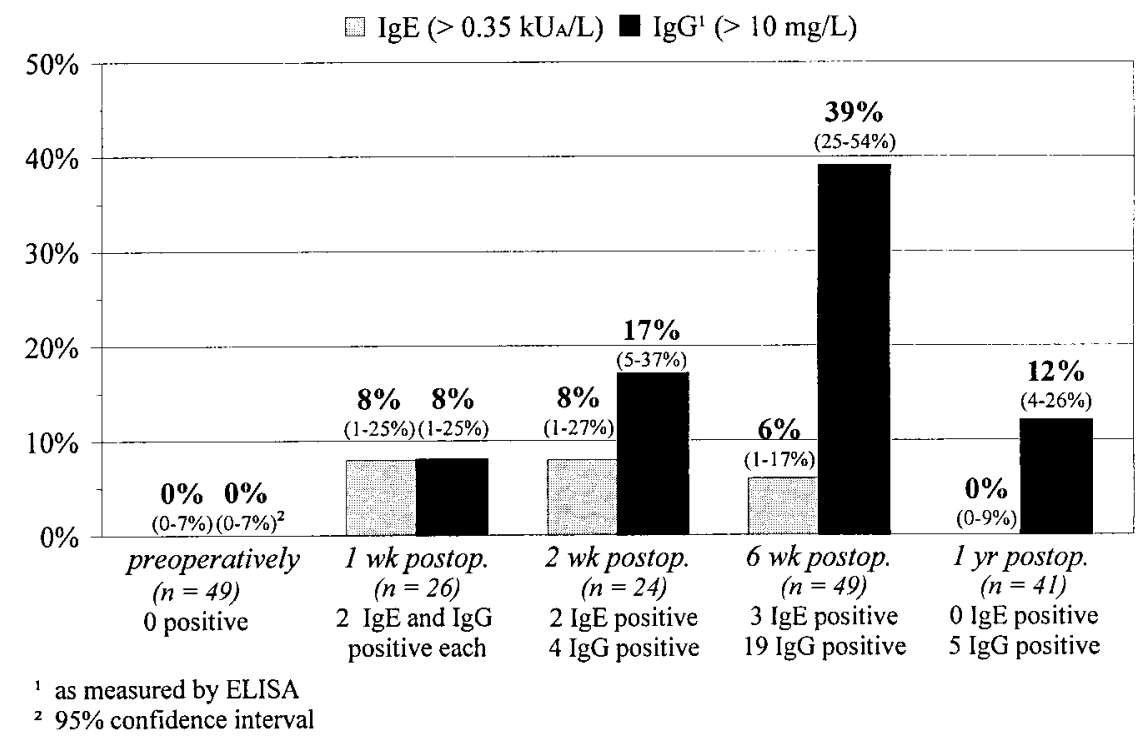

Fig. 1. Prevalence of aprotinin-specific antibodies.

Table III. Course of aprotinin-specific IgE levels in the seven IgE-positive patients

\begin{tabular}{|c|c|c|c|c|c|c|c|c|}
\hline \multirow[b]{3}{*}{ Patients } & \multirow[b]{3}{*}{ Age (mo) } & \multirow{3}{*}{$\begin{array}{c}\text { Fibrin } \\
\text { sealant } \\
(m l)\end{array}$} & \multirow{3}{*}{$\begin{array}{c}\text { Aprotinin } \\
\text { dose } \\
\left(K I U / m^{2} B S A\right)\end{array}$} & \multicolumn{5}{|c|}{ Aprotinin-specific IgE levels $\left(k U_{A} / L, R A S T\right.$-class $)$} \\
\hline & & & & \multirow[b]{2}{*}{ Preoperatively } & \multicolumn{4}{|c|}{ Postoperatively at } \\
\hline & & & & & $1 w k$ & $2 w k$ & $6 w k$ & $1 y r$ \\
\hline 1 & 4 & 2 & 9375 & $<0.35$ & $<0.35$ & $<0.35$ & $0.63(\mathrm{I})$ & $<0.35$ \\
\hline 2 & 8 & 4 & 17,647 & $<0.35$ & $<0.35$ & $<0.35$ & 0.38 (I) & $<0.35$ \\
\hline 3 & 44 & 3 & 6818 & $<0.35$ & $<0.35$ & $0.72(\mathrm{II})$ & $<0.35$ & $<0.35$ \\
\hline 4 & 49 & 3 & 7031 & $<0.35$ & $0.47(\mathrm{I})$ & No serum & $<0.35$ & $<0.35$ \\
\hline 5 & 49 & 6 & 14,031 & $<0.35$ & 6.08 (III) & No serum & $<0.35$ & $<0.35$ \\
\hline 6 & 146 & 2 & 6430 & $<0.35$ & No serum & No serum & 2.6 (II) & $<0.35$ \\
\hline 7 & 47 & 5 & 11,719 & $<0.35$ & No serum & $0.41(\mathrm{I})$ & $<0.35$ & $<0.35$ \\
\hline
\end{tabular}

$K I U / m^{2} B S A$, Kallikrein inhibiting units per square meter body surface area; $B S A$, body surface area.

that is, 7 of 49 children. The course of aprotininspecific IgE levels in the seven IgE-positive patients is shown in Table III. The children who were positive for aprotinin-specific $\operatorname{IgG}$ at 1 and 2 weeks remained positive through at least 6 weeks. Four of the five children who were positive at 1 year had already been positive at 6 weeks. Six children were positive for both $\mathrm{IgG}$ and IgE; this represents $32 \%$ $(13 \%$ to $57 \%$ ) (i.e., 6 of the 19 IgG-positive children).

Total antibody concentrations. Six children presented with elevated total serum IgE levels. Two of these presented with both aprotinin-specific IgE and $\mathrm{IgG}$. Measurements of total serum $\operatorname{IgG}$ were all within the normal range for the respective age except for four children with too-low-for-age total
IgG concentrations. Only one of them presented with aprotinin-specific IgG.

Western blot versus ELISA. When we used the Western blot technique for the 49 sera sampled 6 weeks postoperatively, we detected 12 positive (24\%), 13 questionably positive (27\%), and 24 (49\%) negative sera. The results of ELISA and Western blotting were comparable for very high concentrations and for negative sera. Low concentrations measured by ELISA mostly produced a "questionably positive" with the Western blot technique.

Clinical and pharmacologic influences. In Table IV we show antibody formation together with the factors aprotinin dosage, age, and body surface area. 
Table IV. Clinical and biologic data

\begin{tabular}{|c|c|c|c|c|c|}
\hline$n$ & $\begin{array}{l}\text { Whole } \\
\text { group } \\
49\end{array}$ & $\begin{array}{c}\text { as-IgE } \\
\text { positive } \\
7\end{array}$ & $\begin{array}{c}\text { as-IgE } \\
\text { negative } \\
42\end{array}$ & $\begin{array}{c}\text { as-IgG } \\
\text { positive } \\
19\end{array}$ & $\begin{array}{c}\text { as-IgG } \\
\text { negative } \\
30\end{array}$ \\
\hline \multicolumn{6}{|l|}{ Fibrin sealant } \\
\hline Median (ml) & 2 & 3 & 2 & 3 & 2 \\
\hline $50 \%$ range & $1-3$ & $3-4.5$ & $1-2$ & $2-4.5$ & $1-2$ \\
\hline \multicolumn{6}{|l|}{ Aprotinin dosage } \\
\hline Median (KIU/m² BSA) & 7090 & 9375 & 6410 & 8900 & 6440 \\
\hline $50 \%$ range & $4290-12,500$ & $6930-12,900$ & $3500-12,260$ & $5340-13,850$ & $4290-10,350$ \\
\hline Significance & & \multicolumn{2}{|c|}{$\mathrm{ns}$} & \multicolumn{2}{|c|}{$\mathrm{ns}$} \\
\hline \multicolumn{6}{|l|}{ Age } \\
\hline Median (mo) & 15.2 & 46.6 & 14.0 & 44.0 & 8.0 \\
\hline $50 \%$ range & $4-49$ & $26-49$ & $4-44$ & $10-62$ & $3-30$ \\
\hline Significance & & \multicolumn{2}{|c|}{$\mathrm{ns}$} & \multicolumn{2}{|c|}{ ns } \\
\hline \multicolumn{6}{|l|}{ Body surface area (BSA) } \\
\hline Median $\left(\mathrm{m}^{2}\right)$ & 0.41 & 0.64 & 0.4 & 0.58 & 0.35 \\
\hline $50 \%$ range & $0.32-0.64$ & $0.49-0.65$ & $0.31-0.62$ & $0.39-0.68$ & $0.27-0.53$ \\
\hline Significance & & \multicolumn{2}{|c|}{ ns } & \multicolumn{2}{|c|}{ ns } \\
\hline
\end{tabular}

as, Aprotinin-specific; $n s$, not significant.

Formation of aprotinin-specific antibodies was independent of sex, atopic diathesis, susceptibility to infections, and postoperative long-term medication.

\section{Comments}

In this prospective study we could clearly document that there is a systemic immune response to small topical doses of aprotinin. Our data show an initial rise of the frequency of antibody detection within at least 6 weeks, followed by a distinct decline after 1 year.

As has already been shown for high-dose systemic application, small topical aprotinin doses may also induce an aprotinin-specific IgE response. Yanagihara and Shida ${ }^{14}$ examined patients who received a course of several high-dose infusions of aprotinin for acute pancreatitis. They found aprotinin-specific $\operatorname{IgE}$ in $24 \%(11 \%$ to $39 \%)$ at 2 weeks ( 9 of 37$)$ and $30 \%(12 \%$ to $54 \%)$ at 8 weeks (6 of 20 ).

The prevalence of aprotinin-specific IgG response after topical application is comparable to the prevalence reported after high-dose systemic aprotinin administration. Ruskowski and colleagues ${ }^{15}$ for a group of more than 250 patients with first time systemic high-dose aprotinin application reported a prevalence of aprotinin-specific IgG antibodies of $16.7 \%$ after 4 to 6 weeks and of $46.4 \%$ after 6 to 7 months. In a similar study Pfannschmidt and colleagues ${ }^{16}$ reported $3.6 \%$ aprotinin-specific IgG-positive after 3 to 4 weeks ( 2 of 56) and $46.6 \%$ after 6 months (26 of 56). In contrast to our findings, both studies revealed no aprotinin-specific IgE. This might be due to procedural differences: they used immunoblotting and ELISA and we used FEIA. Another reason may be that they examined adult patients.

IgE antibodies sensitize mast cells and basophil granulocytes by binding to specific receptors on their surface. When an antigen cross-links two surface-bound IgEs, these cells release mediators that cause the clinical symptoms of anaphylaxis. ${ }^{11}$ As for aprotinin, there are two documented cases of anaphylactic reactions with preformed aprotinin-specific $\mathrm{IgE}$ antibodies. ${ }^{20,21}$

The role of antigen-specific IgG for anaphylactic and anaphylactoid reactions is the subject of controversy. Its significance may depend on the distribution of its subclasses ${ }^{13}$ or the ratio of $\mathrm{IgE} / \mathrm{IgG}{ }^{22} \mathrm{It}$ has been shown that specific $\operatorname{IgG}$ subclasses may also trigger severe or even fatal reactions. ${ }^{13,23}$ One explanation may be the so-called immune complex anaphylaxis in which anaphylactic mediators are released by activation of the complement system through the classical and/or the alternate pathway. ${ }^{12}$ Another explanation may be the "homocytotropic activity" of the $\operatorname{IgG}_{4}$ subclass (i.e., its capability of binding to mast cells and thereby acting as an anaphylactic antibody). ${ }^{22,23}$

In the literature from 1963 to 1997 we found 95 cases* of adult patients with anaphylactic or anaphy-

\footnotetext{
* Thirty-eight cases are presented in references 6, 8-10, 14, 17-21; the remainder cannot be cited for reasons of space because these 57 cases are reported in 33 other publications.
} 
lactoid reactions to aprotinin. Preexposure to aprotinin was documented in 63 of these cases. From the clinical data given it was possible to infer the time interval between preexposure and reexposure in 40 cases: the large majority of 27 occurred within 1 week to 3 months, only 13 occurred within a long period of 4 months to 4 years after preexposure. The peak of specific $\operatorname{IgE}$ and $\operatorname{IgG}$ antibody detection in our patients is in accordance with the distribution of reports over time observed in the literature.

The presence of allergen-specific antibodies does not necessarily lead to anaphylactic reactions ${ }^{24}$; they represent a risk factor for allergic reactions. In the literature we found reports of 27 patients with anaphylactic reactions to aprotinin whose sera had been examined for aprotinin-specific $\operatorname{IgE}, 17$ of them were positive postreactively. ${ }^{9,14,15,17,18,20,21}$ Therefore especially in patients with a positive aprotinin-specific antibody screening test the indication for fibrin sealant containing aprotinin or systemic aprotinin should be reconsidered. If the indication is mandatory, we recommend precautionary measures such as pulse oximetry, monitoring of the arterial blood pressure, an intravenous line, and an antiallergic pretreatment at reexposure.

When we looked for predictive parameters for the aptitude to form aprotinin-specific antibodies, our data did not show any. This negative result can be attributed to the number of patients being too small for reliable epidemiologic calculations. Large clinical studies on anesthetic drugs revealed atopy and female gender as risk factors for IgE-mediated reactions. ${ }^{25}$

The benefit of fibrin sealant for local hemostasis has been shown in extensive clinical studies. ${ }^{26,27}$ Although aprotinin extends significantly the time of resorption of the fibrin clot from 3 to more than 28 days, it has not yet been investigated in a clinical study if the aprotinin component is indispensable for that indication. If a stable fibrin clot is necessary for more than a few days, possible alternatives such as $\epsilon$-aminocaproic acid, which stabilizes the clot for 7 days, ${ }^{3}$ or an augmentation of the factor XIII component should be considered.

Contrary to Pfannschmidt and colleagues' findings ${ }^{16}$ that the Western blotting method was more sensitive for $\operatorname{IgG}$ detection than ELISA, we had clearer results using ELISA. This may be due to procedural differences.

In the absence of published data about the close time course of antibody formation, we chose four fixed intervals for blood sampling after a single dose of aprotinin, considering the organizational practicality and the stress for the children and for their parents. Therefore the frequency of antibody formation in the period between 6 weeks and 1 year after exposure remains uncertain.

A limitation of our study is the small number of samples after 1 and 2 weeks because many children had been transferred early to other hospitals. After 6 weeks, all children were reexamined in the division of pediatric cardiology at our hospital. The parents' compliance after 1 year was excellent. All parents were informed in writing about the results and implications.

\section{Conclusions}

The existence of patients forming aprotinin-specific antibodies caused by a previous topical aprotinin application has been proven. There was an increase of aprotinin-specific antibody-positive patients during the first 6 weeks after application of fibrin sealant. Most anaphylactic and anaphylactoid reactions to aprotinin reported in the literature occurred in a comparable time lapse between preexposure and reexposure.

As a practical consequence, any use of aprotinin, even in fibrin sealant, must be carefully documented. If aprotinin use is planned in a patient who has undergone a previous operative procedure, especially during the past several months, previous exposure to aprotinin in any form must be sought.

For patients with recent aprotinin exposure, the indication for aprotinin readministration should be carefully reconsidered. If the expected benefit of fibrin sealant application in these patients outweighs the possible risk of anaphylaxis, we recommend stringent precautionary measures at reexposure.

The usefulness of aprotinin-specific antibody screening remains the subject of further research. The need for aprotinin in fibrin sealants and the use of possible alternatives as stabilizing agents merits consideration.

We express our gratitude to R. Storf, BSc, E. Steil, MD, and I. Besenthal, MD, PhD, for their help.

\section{REFERENCES}

1. Bidstrup BP, Royston D, Sapsford RN, Taylor KM. Reduction in blood loss and blood use after cardiopulmonary bypass with high-dose aprotinin (Trasylol). J Thorac Cardiovasc Surg 1989;97:364-72.

2. Royston D. High-dose aprotinin therapy: a review of the first five years' experience. J Cardiothorac Vasc Anesth 1992;6: 76-100. 
3. Matras H, Jesch W, Kletter G, Dinges HP. Spinale Klebung mit Fibrinkleber. Wien Klin Wochenschr 1978;90:419-25.

4. Schlag G, editor. Fibrin sealing in surgical and non-surgical fields. Vol. 1. Wound healing (1994). Vol. 2. General and abdominal surgery, pediatric surgery (1994). Vol. 3. Plastic surgery, nerve repair, burns (1995). Vol. 4. Orthopedic surgery, maxillofacial surgery (1994). Vol. 5. Neurosurgery, ophthalmic surgery, ENT (1994). Vol. 6. Cardiovascular surgery, thoracic surgery (1995). Vol. 7. Gynecology and obstetrics, urology (1994). Vol. 8. Endoscopy (1995). Berlin, Heidelberg, New York: Springer-Verlag; 1994.

5. Spotnitz WD. Fibrin sealant in the United States: clinical use at the University of Virginia. Thromb Haemost 1995;74: 482-5.

6. Dietrich W, Späth P, Ebell A, Richter JA. Prevalence of anaphylactic reactions to aprotinin: analysis of two hundred forty-eight reexposures to aprotinin in heart operations. J Thorac Cardiovasc Surg 1997;113:194-201.

7. Verstraete M. Clinical application of inhibitors of fibrinolysis. Drugs 1985;29:236-61.

8. Schulze K, Graeter T, Schaps D, Hausen B. Severe anaphylactic shock due to repeated application of aprotinin in patients following intrathoracic aortic replacement. Eur J Cardiothorac Surg 1993;7:495-6.

9. Diefenbach C, Abel M, Limpers B, Lynch J, Ruskowski H, Jugert FK, et al. Fatal anaphylactic shock after aprotinin reexposure in cardiac surgery. Anesth Analg 1995;80:830-1.

10. Martinelli L, Maurelli M, Vigano M. Aprotinin in staged heart transplantation: anaphylactic potential of repeated exposure. Ann Thorac Surg 1996;61:1288-9.

11. Ishizaka T, Ishizaka K. Activation of mast cells for mediator release through $\mathrm{IgE}$ receptors. In: Ishizaka K, editor. Mast cell activation and mediator release. Basel: Karger; 1984. p. 188-235.

12. Colten HR. Immunology: drawing a double-edged sword. Nature 1994;371:474-5.

13. Bergamaschini L, Santangelo T, Faricciotti A, Ciavarella N, Mannucci PM, Agostoni A. Study of complement-mediated anaphylaxis in humans: the role of $\mathrm{IgG}$ subclasses (IgG1 and/or IgG4) in the complement-activating capacity of immune complexes. J Immunol 1996;156:1256-61.

14. Yanagihara Y, Shida T. Immunological studies on patients who received aprotinin therapy. Jpn J Allergy 1985;34:899904.
15. Ruskowski H, Joos A, Kiefer H, Soeperwata R, Wendt G, Merk H, et al. Untersuchungen zur Antigenität von Trasylol in der offenen Herzchirurgie. Thorac Cardiovasc Surg 1993; 41suppl:142.

16. Pfannschmidt J, Steeg D, Jugert F. Routine intraoperative application of high-dose aprotinin in open heart surgery in adults: antibody formation after first exposure. Curr Med Res Opin 1995;13:282-4

17. Dewachter P, Mouton C, Masson C, Guéant JL, Haberer JP. Anaphylactic reaction to aprotinin during cardiac surgery. Anaesthesia 1993;48:1110-1.

18. Kon NF, Masumo H, Nakajima S, Tozawa R, Kimura M, Maeda S. Anaphylactic reaction to aprotinin following topical use of biological tissue sealant. Masui 1994;43:1606-10

19. Mitsuhata H, Horiguchi Y, Saitoh J, Saitoh K, Fukuda H, Hirabayasi Y, et al. An anaphylactic reaction to topical fibrin glue. Anesthesiology 1994;81:1074-7.

20. Scheule AM, Jurmann MJ, Wendel HP, Häberle L, Eckstein FS, Ziemer G. Anaphylactic shock after aprotinin reexposure: time course of aprotinin-specific antibodies. Ann Thorac Surg 1997;63:242-4.

21. Wüthrich B, Schmid P, Schmid ER, Tornic M. IgE-mediated anaphylactic reaction to aprotinin during anaesthesia. Lancet 1992;340:173-4.

22. van der Zee JS, Aalberse RC. The role of IgG in immediatetype hypersensitivity. Eur Respir J 1991;4:91s-6s.

23. Kleinert R. Tod nach Bienenstich: Erstmaliger Nachweis eines $\mathrm{IgG}_{4}$-mediierten anaphylaktischen Schocks. Wien Klin Wochenschr 1983;95:245-8.

24. Kraft D, Wide L. Clinical patterns and results of radioallergosorbent test (RAST) and skin tests in penicillin allergy. Br J Dermatol 1976;94:593-601.

25. Laxenaire MC, Mouton C, Moneret-Vautrin DA, Widmer S, Guéant JL, Maria Y, et al. Drugs and other agents involved in anaphylactic shock occurring during anaesthesia: a French multicenter epidemiological inquiry. Ann Fr Anesth Reanim 1993;12:91-6.

26. Rousou J, Gonzalez-Lavin L, Cosgrove D, Weldon C, Hess P, Joyce $\mathrm{L}$, et al. Randomized clinical trial of fibrin sealant in patients undergoing resternotomy or reoperation after cardiac operations. J Thorac Cardiovasc Surg 1989;97:194-203.

27. Borst HG, Haverich A. Clinical use of fibrin adhesive: summary. Thorac Cardiovasc Surg 1982;30:241. 